\title{
Genetic and Quantitative Trait Locus Analysis of Cell Wall Components and Forage Digestibility in the Zheng58 x HD568 Maize RIL Population at Anthesis Stage
}

\author{
Kun Lit, Hongwu Wang ${ }^{\dagger}$, Xiaojiao Hu, Feiqian Ma, Yujin Wu, Qi Wang, Zhifang Liu* and \\ Changling Huang*
}

Institute of Crop Sciences, Chinese Academy of Agricultural Sciences, Beijing, China

\section{OPEN ACCESS}

Edited by:

Rosa Ana Malvar,

Misión Biológica de Galicia (CSIC),

Spain

Reviewed by:

Rogelio Santiago,

University of Vigo, Spain

Yves Barrière

Institut National de la Recherche

Agronomique (INRA), France

*Correspondence:

Zhifang Liu

liuzhifang@caas.cn

Changling Huang

huangchangling@caas.cn

tThese authors have contributed equally to this work.

Specialty section:

This article was submitted to Crop Science and Horticulture,

a section of the journal

Frontiers in Plant Science

Received: 02 June 2017 Accepted: 08 August 2017 Published: 24 August 2017

Citation:

Li K, Wang H, Hu X, Ma F, Wu Y, Wang Q, Liu Z and Huang C (2017) Genetic and Quantitative Trait Locus

Analysis of Cell Wall Components and Forage Digestibility in the Zheng58 $\times$ HD568 Maize RIL

Population at Anthesis Stage.

Front. Plant Sci. 8:1472.

doi: 10.3389/fpls.2017.01472
The plant cell wall plays vital roles in various aspects of the plant life cycle. It provides a basic structure for cells and gives mechanical rigidity to the whole plant. Some complex cell wall components are involved in signal transduction during pathogenic infection and pest infestations. Moreover, the lignification level of cell walls strongly influences the digestibility of forage plants. To determine the genetic bases of cell wall components and digestibility, quantitative trait locus (QTL) analyses for six related traits were performed using a recombinant inbred line (RIL) population from a cross between Zheng58 and HD568. Eight QTL for in vitro neutral detergent fiber (NDF) digestibility were observed, out of which only two increasing alleles came from HD568. Three QTL out of ten with alleles increasing in vitro dry matter digestibility also originated from HD568. Five-ten QTL were detected for lignin, cellulose content, acid detergent fiber, and NDF content. Among these results, 29.8\% (14/47) of QTL explained $>10 \%$ of the phenotypic variation in the RIL population, whereas $70.2 \%$ (33/47) explained $\leq 10 \%$. These results revealed that in maize stalks, a few large-effect QTL and a number of minor-effect QTL contributed to most of the genetic components involved in cell wall biosynthesis and digestibility.

Keywords: QTL, maize, cell wall, lignin, digestibility

\section{INTRODUCTION}

The plant cell wall is an amorphous matrix that surrounds the cell membrane. Plant cell walls provide the basic mechanical support that allows plants to stand upright. Moreover, microbial infection usually induces lignification of the cell wall, which protects plants from further harm. Cell wall architecture plays important roles in plant responses to various abiotic stresses, such as drought, flooding, heat, cold, and salt and is essential in stress sensing and signal transduction (Gall et al., 2015). Furthermore, the cell walls of forage plants are the main resources for animal feeding. Lignocellulose biomass is also considered to be a source of renewable energy for the production of biofuel (Bhalla et al., 2013).

From a livestock feeding perspective, the primary goal is to focus on good forage quality, which is usually defined as a high forage intake and digestibility. The plant cell wall is a composite 
material that consists mainly of cellulose (CEL), hemicellulose, and lignin (LIG) (Chen, 2014). These three organic compounds are also major components of plant fiber and forage dry matter. Since the concentrations of cell wall constituents are correlated with forage intake and digestibility, they are regarded as the most important factors in forage utilization (Paterson et al., 1994). Previous research has demonstrated that each cell wall component has a specific digestibility. The digestibility of CEL ranges from 50 to $90 \%$, with hemicellulose being $20-80 \%$ digestible (Kebede et al., 2016; and reference therein). Thus, to evaluate the forage quality of plants, several chemical analysis methods have been introduced to measure the cell wall contents. Fiber content is usually quantified as neutral detergent fiber (NDF) and acid detergent fiber (ADF), whereas LIG content can be measured as acid detergent lignin (ADL). Neutral detergent fiber mainly consists of CEL, hemicellulose, and LIG (Krakowsky et al., 2003). After hemicelluloses are solubilized by treatment with an acid detergent, CEL and LIG, which mainly comprise ADF, are left in the residue of the cell wall (Truntzler et al., 2010). Consequently, hemicellulose content can be determined by NDF minus ADF, and CEL content is assumed to be the difference between ADF and ADL (Jess, 1986; Truntzler et al., 2010). Although LIGs are the most difficult components for microorganisms in the rumen of an herbivore to digest, the correlations between digestibility and lignification have been shown to vary according to the genetic background of the plant (Barrière et al., 2003). Moreover, the LIG levels in maize and other species were not shown to be well-correlated with the enzyme-mediated digestibility of the cell wall (Marriott et al., 2014; Penning et al., 2014; Guzzo de Carli Poelking et al., 2015; Cass et al., 2016). In addition to the contents of specific cell wall components, the associations and cross-linkages between polysaccharides and LIGs also contribute to the digestibility of cell wall (Truntzler et al., 2010). It seems impossible to improve the forage quality by selecting only for low amount of LIGs or other cell wall components. Measuring forage and cell wall digestibility directly allows breeders to evaluate the digestibility level of the genetic germplasm. Since in vivo methods for detecting digestibility are complex and expensive for breeding programs, in vitro methods for estimating digestibility, which include in vitro neutral detergent fiber digestibility (IVNDFD) and in vitro dry matter digestibility (IVDMD) methods (Marten and Barnes, 1979; Hatfield et al., 1994), have been introduced into forage analyses. In addition, the introduction of near-infrared reflectance spectroscopy (NIRS) provides rapid estimates of cell wall components and digestibility at lower costs and with greater accuracy (Shenk and Westerhaus, 1994).

Through forward genetic screening, a set of brown-midrib maize mutants that showed decreased LIG contents and improved digestibility by ruminant animals were discovered (Cherney et al., 1991; Barriere and Argillier, 1993; Marita et al., 2003; Vermerris et al., 2007). However, the modification of one monolignol-related gene in these mutants causes larger changes than expected in the cell wall polymers (Courtial et al., 2013). Moreover, the application of the brown-midrib mutants in improving forage quality also shows a negative effect on biomass yield-related traits (Li and Chapple, 2010; Simmons et al., 2010).
Therefore, LIG pathway mutants cannot be successfully used to improve forage digestibility due to their side effects. Breeding for high digestibility in forage maize with marker-assisted selection (MAS) is an alternative approach for improving forage quality. Dissecting the genetic basis of cell wall-related traits has greatly influenced the understanding of the biosynthetic pathways of cell wall components and has provided useful molecular markers for MAS in forage breeding. Over the last two decades, quantitative trait locus (QTL) analyses of the composition and digestibility traits of the cell wall have been performed in maize (Lübberstedt et al., 1997a,b; Bohn et al., 2000; Barriere et al., 2001; Méchin et al., 2001; Papst et al., 2001; Roussel et al., 2002; Cardinal et al., 2003; Fontaine et al., 2003; Krakowsky et al., 2003, 2005, 2006; Barrière et al., 2007; Riboulet et al., 2008); these studies have identified more than 400 QTL across the maize genome. However, the use of a small number of early generation markers, such as Restriction Fragment Length Polymorphism (RFLP) and Simple Sequence Repeats (SSR), caused low resolution in some previous studies. With the development of genotyping technologies, single nucleotide polymorphism (SNP) markers have been widely used in linkage and association studies in maize (Li et al., 2012, 2013, 2014; Shutu et al., 2012; Peiffer et al., 2014). Compared with SSR markers, SNPs are more accurate, less time-consuming, and less costly to identify; moreover, SNPs are more useful for improving the resolution of genetic mapping (Yan et al., 2010; Yang et al., 2011; Shutu et al., 2012). Currently, SNP genotyping is usually performed using DNA chips (Yan et al., 2009, 2010; Ganal et al., 2011; Li et al., 2014) and genotype-by-sequencing (GBS) approaches (Gore et al., 2009; Lai et al., 2010; Chia et al., 2012; Jiao et al., 2012; Bukowski et al., 2015).

In most of the previous QTL mapping studies of cell wall component and digestibility traits were performed at the silage stage. Whereas cell wall components accumulation in plant is a dynamic process. In this process, a lot of genes or locus function in cell wall component biosynthesis in different organs and growth stages. Besides silage stage, anthesis stage is also a key period for forage maize growth, which leads a change from vegetative growth to reproductive growth. In this study, a maize Zheng58 $\times$ HD568 recombinant inbred line (RIL) population was developed and genotyped using a GoldenGate maize SNP assay, which contains 3,072 SNPs. Our objectives were to identify QTL associated with the cell wall composition and digestibility traits of maize stalks at the anthesis stage and dissect the genetic architecture of the target traits evaluated herein.

\section{MATERIALS AND METHODS}

\section{Germplasm and Field Experiments}

A RIL population consisting of 220 lines was developed by single seed descent (SSD) up until the F10 generation in a cross between inbred lines Zheng58 and HD568, which are the parental lines of the elite commercial hybrid Zhongdan909 in China. Zheng58 originated from BSSS group, HD568 came from Tangsipingtou (TSPT) germplasm which is a traditional heterotic group used in maize breeding of China. All F10 RILs and the two parents were planted in a randomized complete block design with two 
replicates in Hainan in 2012 and Beijing in 2013. Each line was grown in a single $2.5 \mathrm{~m}$ row with $0.67 \mathrm{~m}$ between rows and a planting density of 45,000 plants/ha.

\section{Phenotyping Methods}

At the anthesis stage, the second-fifth internodes above the ground were collected from six plants of each line. All samples were immediately enzyme deactivated at $105^{\circ} \mathrm{C}$ for $30 \mathrm{~min}$ in a forced air oven and air-dried for 10-14 days. Dried stalk samples were ground with a mill and filtered through a screen with a mesh size of $0.1 \mathrm{~mm}$. Cellulose, LIG, ADF, NDF, and IVDMD were estimated using NIRS. Before the measurements, the stalk samples were dried at $45^{\circ} \mathrm{C}$ for $48 \mathrm{~h}$ to exclude the influence of moisture. The samples were scanned through a near-infrared reflectance spectrophotometer (VECTOR22/N; BURKER Optik, Ettlingen, Germany). Cellulose, LIG, ADF, NDF, and IVDMD were determined using NIRS prediction equations developed for maize plants. A modified partial least squares approach implemented in OPUS 6.0 Bruker software was used to fit the calibration equations (Shenk and Westerhaus, 1991). The coefficients of determination for cross-validation $\left(R_{\mathrm{CV}}^{2}\right)$ and external validation $\left(R_{\mathrm{Val}}^{2}\right)$ were $90.5 \%$ and $92.7 \%$ for $\mathrm{LIG}, 94.0 \%$ and $96.7 \%$ for CEL, $93.6 \%$ and $94.6 \%$ for ADF, $95.3 \%$ and $96.5 \%$ for NDF, and $90.2 \%$ and $91.2 \%$ for IVDMD, respectively.

Because CEL and LIG are components of the cell wall, they were expressed as the percentage of NDF in the QTL analysis (CEL/NDF, LIG/NDF). In addition to the traits mentioned above, cell wall digestibility was investigated according to Struik (1983) and Dolstra and Medema (1990). The IVNDFD was estimated with the following formula: IVNDFD $=100 \times($ IVDMD- $(100-N D F) / N D F$, assuming that the non-NDF part of the plant was completely digested.

\section{Phenotypic Data Analyses}

All statistical analyses were performed using $\mathrm{R}$ software, version 3.3.2 ${ }^{1}$. To eliminate the environmental effects resulting from multiple environments, we fitted a mixed linear model to calculate the best linear unbiased prediction (BLUP) value for each line: $y_{i}=\mu+g_{i}+e_{i}+\varepsilon_{i}$. In this equation, $y_{i}$ represents the phenotype of the " $i$ "th line, $\mu$ is the grand mean value of the target trait in all environments, $g_{i}$ represents the genetic effect, $e_{i}$ is the environmental effect (replications in each environment were also treated as environmental effects in the BLUP mixed model), and $\varepsilon_{i}$ is the random error. The grand mean was fitted as a fixed effect, and genotype and environment were considered as random effects. The estimated BLUP, which was obtained using the linear mixed effect function "lmer" in the "lme4" package of $\mathrm{R}$, was denoted as the sum of the grand mean and genetic effects of each line. The BLUP values of each line were used as the phenotypic values for QTL mapping.

The aov function in $\mathrm{R}$ was used to dissect the phenotypic variance in different environments. The model used for the analysis of variance was $y_{i l k}=\mu+e_{l}+r_{k(l)}+f_{i}+(f e)_{i l}+\varepsilon_{i l k}$, where $e_{l}$ is the environmental effect of the "l"th environment, $r_{k(l)}$ is the effect of replications within environments, $f_{i}$ represents

${ }^{1}$ http://www.R-project.org the genetic effect of the " $i$ "th line, $(f e)_{i l}$ is the interaction effect between genetic and environment effects, and $\varepsilon_{i l k}$ is the residual error. All of the effects were considered to be random. Broad sense heritability was calculated as $h^{2}=\sigma_{g}^{2} /\left(\sigma_{g}^{2}+\sigma_{g e}^{2}+\sigma_{\varepsilon}^{2} / r e\right)$, where $\sigma_{g}^{2}$ represents the genetic variance, $\sigma_{g e}^{2}$ is the variance of interaction between the genotype and the environments, $\sigma_{\varepsilon}^{2}$ is the residual error variance item, and $e$ and $r$ are the number of environments and replications in each environment, respectively. The 95\% confidence intervals of the $h^{2}$ were calculated following the method of Knapp et al. (1985).

\section{Genotyping and Genetic Map Construction}

Leaf tissues were collected from all 220 RILs and their parents and freeze-dried at $-60^{\circ} \mathrm{C}$. Genomic DNA was extracted using the modified CTAB method (Murray and Thompson, 1980) and used for genotyping with the MaizeSNP3K DNA-Chip, a subset of the Illumina MaizeSNP50 BeadChip (Ganal et al., 2011) that contains 3,072 SNPs. Single nucleotide polymorphism genotyping was performed on the Illumina GoldenGate SNP genotyping platform (Fan et al., 2006) at the National Maize Improvement Center of China, China Agricultural University. The quality of each SNP was manually controlled as described by Yan et al. (2010), and SNPs with poor quality were excluded from further analysis.

PLINK (Purcell et al., 2007) was used to estimate the minor allele frequency (MAF), missing rate, and heterozygosity for each SNP as well as the missing rate and heterozygosity for each line. After quality control, the SNPs with a missing rate $\leq 20 \%$, heterozygosity $\leq 10 \%$, and MAFs $\geq 0.05$ were used to construct the genetic linkage map with QTL ICI-Mapping V3.2 (Meng et al., 2015). Linkage groups were established with the QTL IciMapping software V3.2 ${ }^{2}$. The polymorphism markers between two parents were grouped with a minimum logarithm of the odds (LODs) of 8.0. Recombination frequencies were converted into centimorgans using the Kosambi mapping function (Kosambi, 2011). Ordering and rippling procedures were performed with the "nnTwoOpt" algorithm and "the sum of adjacent recombination frequencies (SARFs)."

\section{QTL Mapping}

Best linear unbiased prediction values across environments were used in QTL mapping of the cell wall components and digestibility traits. A whole genome scan was performed using composite interval mapping (Zeng, 1994) implemented in Windows QTL Cartographer 2.5 (Basten et al., 2005). The scanning interval between markers was set at $0.5 \mathrm{cM}$, and the window size was set at $10 \mathrm{cM}$. Model 6 of the Zmapqt module was selected for detecting QTLs and estimating their effects. A forward-backward stepwise regression with five controlling markers was used to control the background signals from flanking markers. The threshold LOD values used to declare the putative QTLs were estimated by permutation tests with a minimum of 1,000 replicates at a significance level of $p<0.05$ (Churchill and Doerge, 1994). The confidence intervals for the

\footnotetext{
${ }^{2}$ http://www.isbreeding.net/software/default.aspx?type=list\&class $=20$
} 
locations of the QTLs were determined via one-LOD support intervals to each side of the position of the maximum LOD (Lander and Botstein, 1989). To estimate the percentage of the phenotypic variance explained by all QTLs, multiple-interval mapping was performed using the Bayesian Information Criteria (BIC-M0) in Windows QTL Cartographer 2.5 (Kao et al., 2004).

\section{RESULTS}

\section{Phenotypic Variability and Heritability}

Among the six investigated traits, significant differences were observed between the two parental lines only in IVNDFD and IVDMD. According to the BLUP values of the parental lines, Zheng58 showed higher digestibility (IVNDFD and IVDMD) than HD568 (Table 1). The means of the RIL population were close to the mid-parent values for all measured traits. A normal distribution was observed for each trait (Figure 1). The ANOVA results showed that both genotype and environmental effects significantly affected the cell wall components and digestibility $(p<0.01)$. Based on the mean square (MS) values, genotype $x$ environment interaction effects were lower than genotype effects for all traits (Table 1). Broad sense heritability $\left(H^{2}\right)$ estimates were moderate for all investigated traits and ranged from 0.43 to 0.70 .

\section{Genetic Linkage Map and QTL Analysis}

After quality control, 1,358 SNP markers were used to construct the genetic map. The total length of the linkage map for the RIL

TABLE 1 | Phenotypic variation of cell wall components and digestibility traits in the RIL population.

\begin{tabular}{|c|c|c|c|c|c|c|c|c|c|}
\hline Traits & Zheng58 ${ }^{a}$ & HD568 $^{a}$ & Mean & $\operatorname{Max}$ & Min & Genob $^{b}$ & Geno $\times E^{E n v}{ }^{c}$ & $h^{2 \mathrm{~d}}$ & $\mathrm{Cl}^{\mathrm{e}}$ \\
\hline ADF & 31.89 & 35.90 & $35.36 \pm 2.44$ & 41.88 & 27.84 & $54.82^{* *}$ & $20.00^{* *}$ & 0.64 & $0.52-0.72$ \\
\hline ADL/NDF & 14.65 & 14.45 & $14.61 \pm 0.41$ & 15.77 & 13.71 & $2.66^{* *}$ & $1.37^{* *}$ & 0.49 & $0.33-0.61$ \\
\hline CEL/NDF & 47.39 & 48.71 & $48.80 \pm 1.35$ & 53.69 & 45.08 & $23.92^{* *}$ & $11.73^{* *}$ & 0.51 & $0.36-0.62$ \\
\hline IVDMD & 63.19 & 58.17 & $59.53 \pm 3.42$ & 69.95 & 49.38 & $106.81^{* *}$ & $23.74^{* *}$ & 0.63 & $0.52-0.72$ \\
\hline IVNDFD & 24.26 & 21.24 & $22.98 \pm 2.31$ & 30.56 & 18.18 & $101.13^{* *}$ & $57.73^{* *}$ & 0.43 & $0.25-0.56$ \\
\hline NDF & 48.04 & 52.17 & $51.80 \pm 3.21$ & 60.57 & 43.32 & $77.93^{* *}$ & $39.10^{* *}$ & 0.70 & $0.60-0.77$ \\
\hline
\end{tabular}

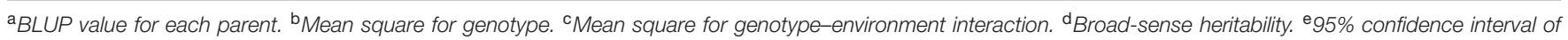
broad-sense heritability. ** Significant at $p<0.01$.
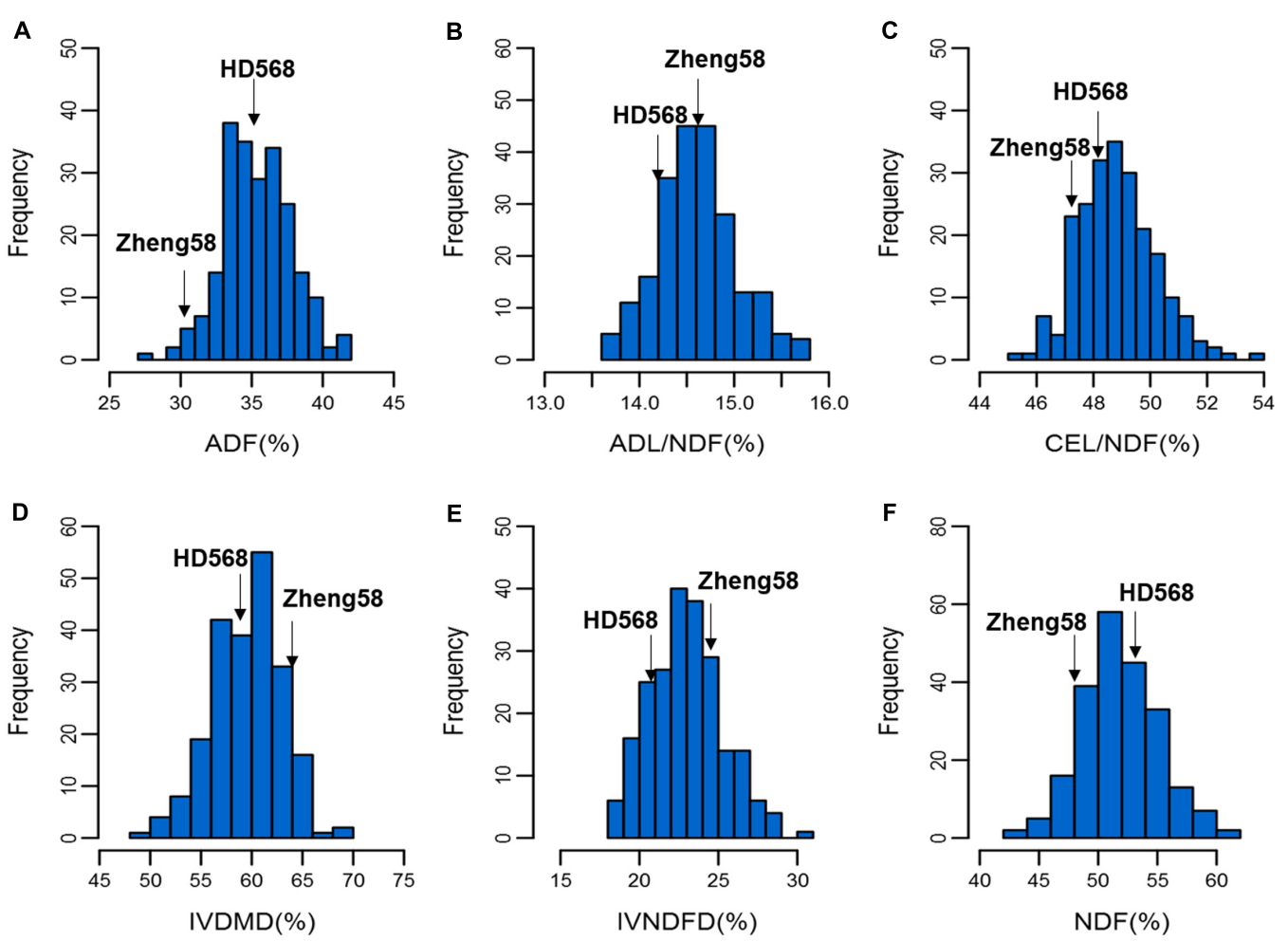

FIGURE 1 | Distribution of cell wall components and digestibility in the RIL population. The frequency distributions of ADF, ADL/NDF, CEL/NDF, IVDMD, IVNDFD, and NDF in the RIL population are shown in (A-F), respectively. 
population was $1,985.6 \mathrm{cM}$. The average interval of the whole genome scale was $1.5 \mathrm{cM}$ and ranged from 1.0 to $2.2 \mathrm{cM}$ across 10 chromosomes (Supplementary Data Sheet $\mathbf{1}$ ).

The empirical threshold LOD values for the genome-wide significance $(p<0.05)$ were determined to be 3.2 for digestibility traits (IVNDFD and IVDMD) and 3.3 for other four traits after 1,000 permutations. In total, 47 QTL controlling cell wall components and digestibility traits were detected; these QTL corresponded to 10 genomic regions due to the co-localization of different traits (Table 2 and Figure 2). These loci were distributed across eight chromosomes except 3 and 6. Each QTL explained between 4.2 (ADF) and $18.9 \%$ (IVDMD) of the phenotypic variation. All additive QTLs mapped for each trait accounted for a moderate proportion of the total phenotypic variation, which ranged from 25.5 (ADL/NDF) to 47.4\% (IVDMD) (Table 2).

For ADF content, six QTL were detected on chromosomes 1, 2, 7, 8, and 9. Among these QTL, adf9-2, with the largest effect $(12.3 \%$ of the phenotypic variation) was located on chromosome 9. The HD568 allele at this locus contributed an additive effect of $0.85 \%$ for ADF concentration. Another important locus for ADF content, adf9-1, which explained $11.1 \%$ of the phenotypic variation with an additive of $0.81 \%$, was also located on chromosome 9. Moreover, another major effect QTL (adf2) that explained more than $10 \%$ of the phenotypic variation was found on chromosome 2 . The allele from Zheng58 at this locus was associated with an increase in ADF content.

Five QTL were significantly associated with ADL/NDF. These QTL were distributed on chromosomes 7, 8, and 9 and explained $25.5 \%$ of the total phenotypic variation. A QTL cluster detected on chromosome 9 consisted of three adjacent QTL that explained $11.1,11.1$, and $9.1 \%$ of the phenotypic variation, respectively. With the exception of adl7, the alleles of these QTLs that increased ADL/NDF came from Zheng58.

A total of 10 QTL controlling CEL/NDF that explained $34.9 \%$ of the total phenotypic variation were distributed on chromosomes 2, 4, 5, and 9. These QTL were located in four genomic regions. The strongest QTL, cel2-2, explained $11.6 \%$ of the phenotypic variation, and the Zheng58 allele had an additive effect of $0.49 \%$ for increasing CEL/NDF. The phenotypic variance explained by the other nine QTL ranged from 4.7 to $7.4 \%$. With the exception of two QTL on chromosome 5 (cel5-1 and cel5-2), the alleles of these nine QTL with increasing effects came from Zheng58.

For IVDMD, nine additive effect QTL that explained $47.4 \%$ of the total phenotypic variation were located on chromosomes 2 , 7, 8, 9, and 10. Among all the identified QTLs for IVDMD, two QTL on chromosome 9 accounted for $>15 \%$ of the phenotypic variation (Table 2). The other QTL explained only $4.3-8.2 \%$ of the phenotypic variation. HD568 alleles at three loci, ivdmd2-1, ivdmd2-2, and ivdmd10, contributed to increased IVDMD.

Eight QTL were associated with IVNDFD and accounted for $39.1 \%$ of the total phenotypic variation. These QTL were located on chromosomes 8, 9, and 10 and explained $6.3-11.2 \%$ of the variation. With the exception of ivndfd10-1 and ivndfd10-2, the alleles of these eight QTL with increasing effects came from Zheng58.
Four out of nine QTL for NDF accounted for $>10 \%$ of the phenotypic variation. The strongest QTL, ndf9-1, which was flanked by the markers PZE-109027216 and PZE-109049079, explained $14.2 \%$ of the phenotypic variation. Four QTL were located on chromosome 2, and Zheng58 alleles at these loci had additive effects that increased NDF. The alleles of the other five QTL with increasing effects came from HD568. Collectively, the nine QTL for NDF explained $41.7 \%$ of the total phenotypic variation.

In addition to the individual additive QTL, five pairs of epistatic QTL involving nine loci were identified for ADF, CEL/NDF, IVNDFD, and NDF (Table 3 ). The proportion of total phenotypic variance explained by all epistatic QTL ranged from 2.2 to $4.7 \%$. With the exception of ivndfd10-1 and ivndfd10-2, the combination of alleles at all interacting loci with increasing contributions were inherited from different parents.

\section{Co-localization of Individual QTL for Each Trait}

A comparison of the QTL for different traits revealed a conspicuous QTL hotspot on chromosome 9. This QTL cluster was flanked by SNP markers PZE-109016787 and PZE109076761 and had a genetic interval from 55.7 to $90.3 \mathrm{cM}$. Two-three QTL for each trait were found in this genomic region. The QTL located within this genomic region contributed a large proportion (ranging from 4.7 to $18.9 \%$ ) of the phenotypic variation for each trait. The QTL for ADF, ADL/NDF, and NDF on chromosome 8 (adf8, adl8, and $n d f 8)$ shared a common left flanking marker, SYN10430. Moreover, the LOD score plot for chromosome 8 (Figure 2) showed another potential QTL peak for IVDMD within this overlapped QTL region, though without significance (LOD $\geq 3.3$ ). The additive effect QTL on chromosome 2 were found sharing overlapping confidence interval and explained 11.8, 5.7, and $11.3 \%$ of the phenotypic variation of ADF, IVDMD, and NDF, respectively (Figure 2). The overlapped region of these QTL spanned a $2.2 \mathrm{cM}$ genetic distance and ranged from 62.7 to $64.9 \mathrm{cM}$. In addition to chromosome 2, overlapping QTL for ADF, IVDMD, and NDF were also detected on chromosome 7 and ranged from 84.6 to $86.8 \mathrm{cM}$.

\section{DISCUSSION}

\section{Phenotypic Variation and Heritability}

In the present study, a panel consisting of 220 RILs was used to determine the genetic architecture of cell wall components and digestibility. Based on the BLUP values of two parents across different environments, HD568 showed relatively higher ADF and NDF contents and lower forage and cell wall digestibility compared with Zheng58 (Table 1). Transgressive segregation for each trait was observed in the RILs (Figure 1), which could be attributed to the pyramiding of advantageous alleles at different loci. The ANOVA results showed that environmental and genetic effects played important roles in affecting phenotypic variance. Previous studies have shown significant variations in the broad sense heritability of each cell wall component and 
TABLE 2 | Summary of QTL for cell wall components and digestibility traits in the RIL population.

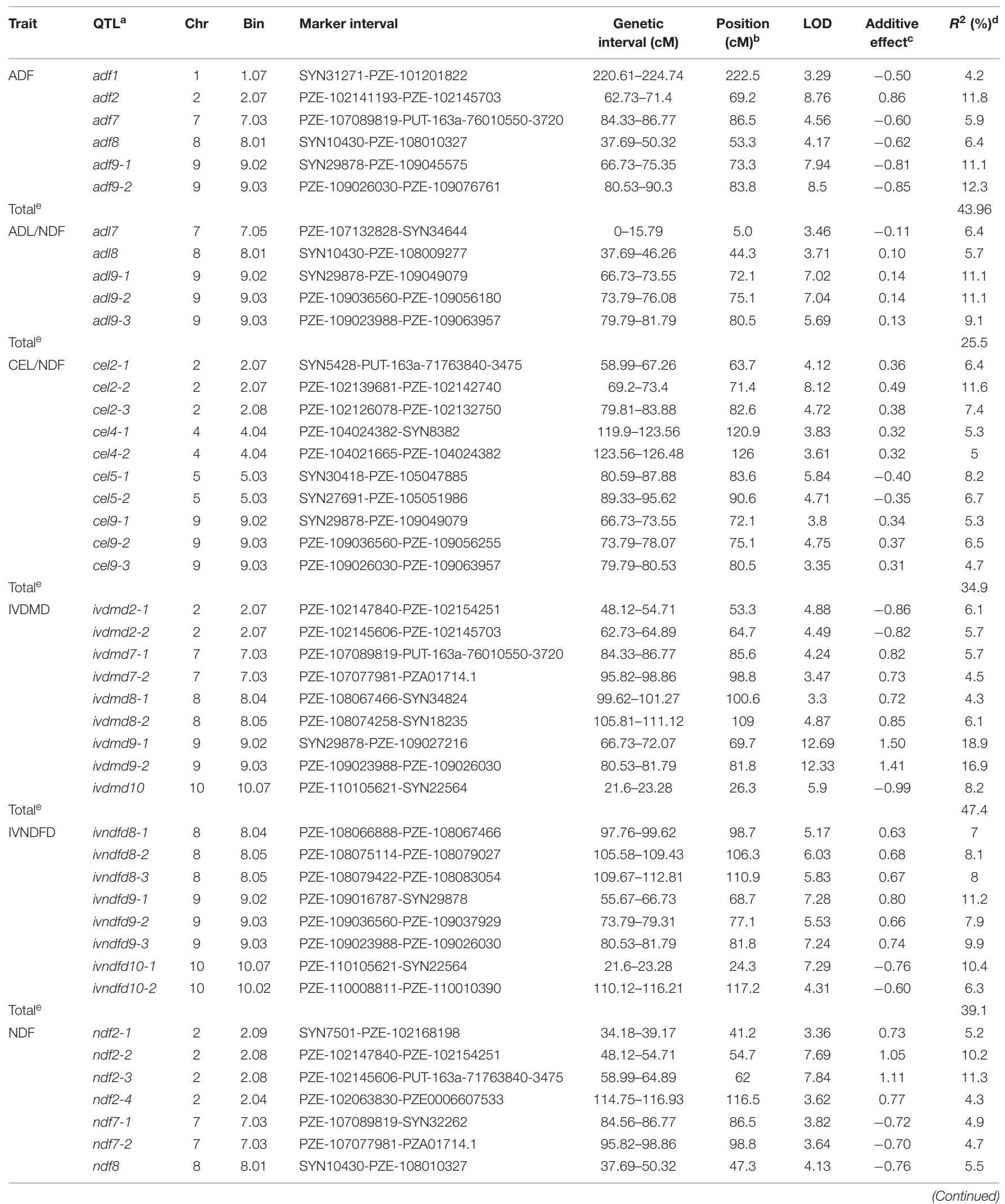


TABLE 2 | Continued

\begin{tabular}{|c|c|c|c|c|c|c|c|c|c|}
\hline Trait & QTL $^{a}$ & Chr & Bin & Marker interval & $\begin{array}{c}\text { Genetic } \\
\text { interval (cM) }\end{array}$ & $\begin{array}{l}\text { Position } \\
(\mathrm{cM})^{\mathrm{b}}\end{array}$ & LOD & $\begin{array}{l}\text { Additive } \\
\text { effect }^{c}\end{array}$ & $R^{2}(\%)^{\mathrm{d}}$ \\
\hline & $n d f 9-1$ & 9 & 9.03 & PZE-109027216-PZE-109049079 & $72.07-73.55$ & 73.3 & 10.27 & -1.22 & 14.2 \\
\hline & $n d f 9-2$ & 9 & 9.03 & PZE-109026030-PZE-109076761 & $80.53-90.3$ & 84.8 & 8.57 & -1.15 & 12.7 \\
\hline Total $^{e}$ & & & & & & & & & 41.7 \\
\hline
\end{tabular}

${ }^{a}$ Each QTL was named with its associated trait name and chromosomal location. Different numbers following the dash indicate different QTL on the same chromosome.

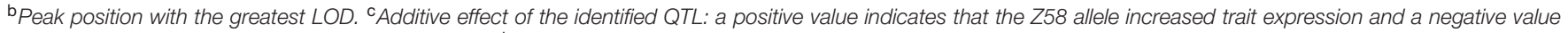

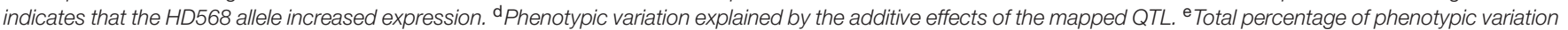
explained by all additive effects of the mapped QTL for each trait.

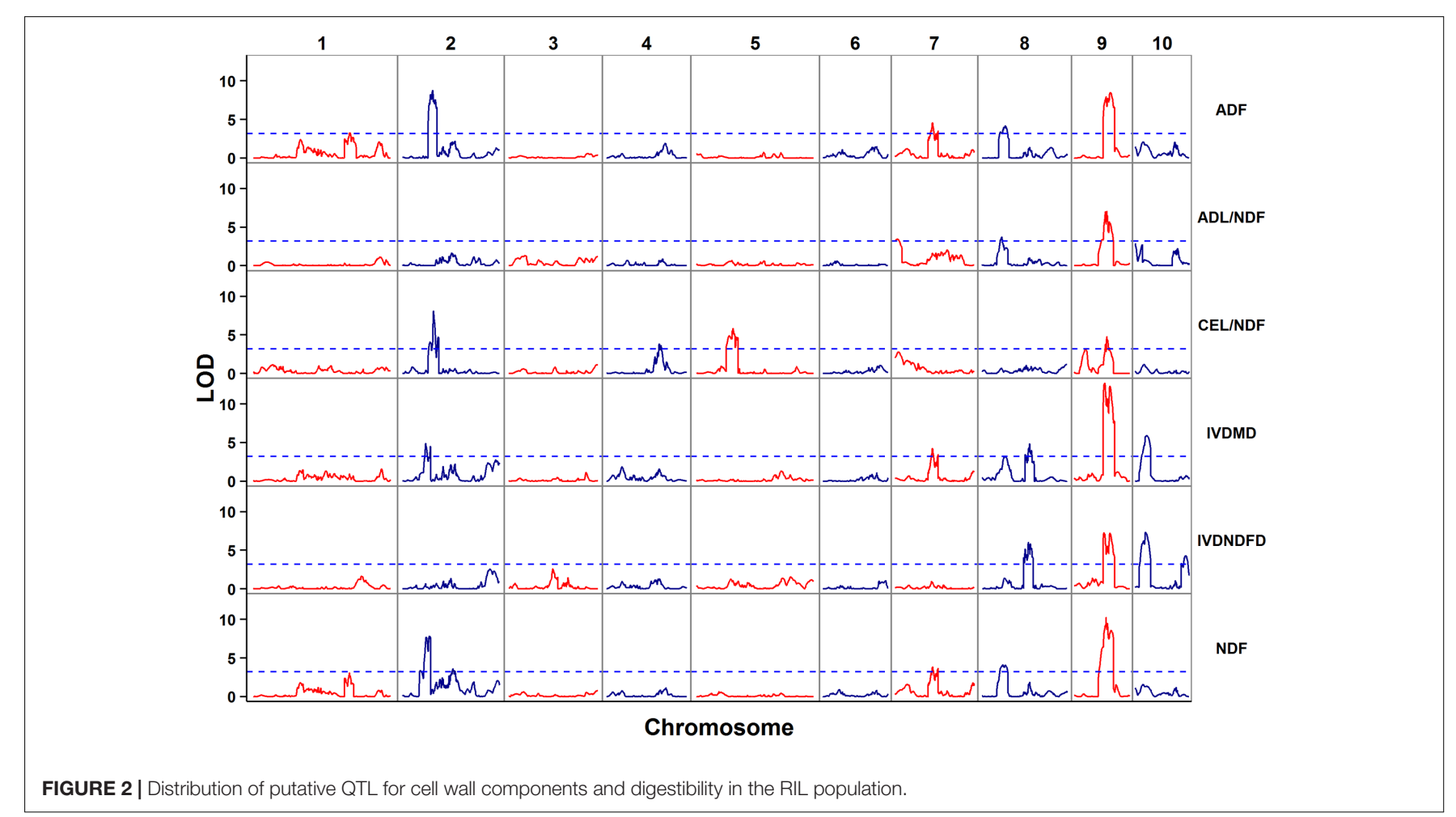

digestibility trait, which ranged from 0.49 to 0.96 (Lübberstedt et al., 1997a,b; Bohn et al., 2000; Barriere et al., 2001; Méchin et al., 2001; Papst et al., 2001; Roussel et al., 2002; Cardinal et al., 2003; Fontaine et al., 2003; Krakowsky et al., 2003, 2005, 2006; Barrière et al., 2007; Riboulet et al., 2008). As in previous studies, the broad sense heritability estimates of the present study were moderate for the QTL analysis, ranging from 0.43 (IVNDFD) to 0.70 (NDF). The significant variation of heritability between different studies demonstrates the complexity of the genetic architecture of cell wall components and digestibility. Further characterization of these traits in additional bi-parental segregating populations is needed to reconcile these differences in heritability values.

\section{Genetic Architecture of Maize Cell Wall Components and Digestibility at the Anthesis Stage}

Thus far, numerous QTL related to different cell wall components and digestibility traits in maize have been investigated in previous studies (Lübberstedt et al., 1997a,b; Bohn et al., 2000; Barriere et al., 2001; Méchin et al., 2001; Papst et al., 2001; Roussel et al., 2002; Cardinal et al., 2003; Fontaine et al., 2003; Krakowsky et al., 2003, 2005, 2006; Barrière et al., 2007; Riboulet et al., 2008). These QTL can affect the phenotypic variations of silage quality and cell wallrelated traits. Among these QTL mapping studies, three of them were performed at anthesis stage (Krakowsky et al., 2003, 2005, 2006). In the present study, 47 QTL were detected in the RIL population, with 4-10 QTL for each trait explaining $4.2-18.9 \%$ of the phenotypic variation in the Zheng58 $\times$ HD568 RIL population (Figure 2 and Table 2). Among these QTL, 29.8\% could explain more than $10 \%$ of the phenotypic variation. All these findings together with previous QTL mapping studies about cell wall components and digestibility traits revealed that a few major effect QTLs and some minor effect QTLs provide most of the genetic bases of cell wall components and digestibility in maize. 


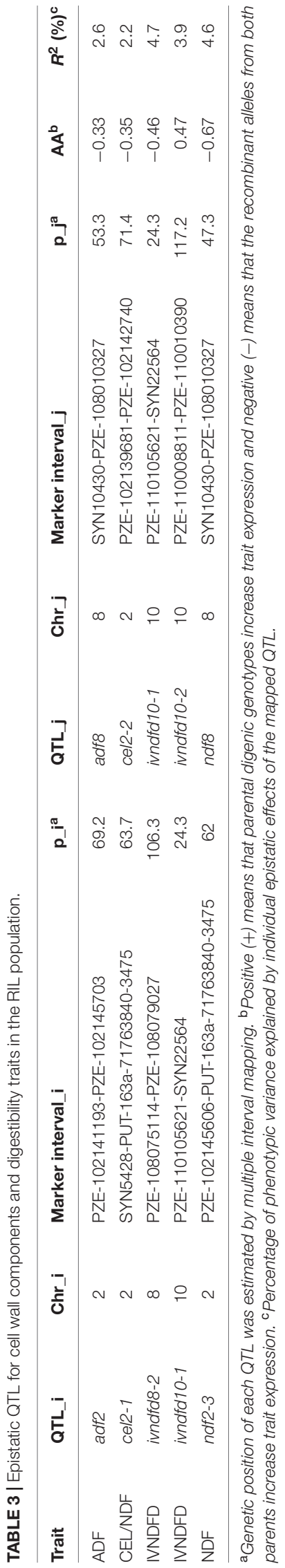

The low resolution caused by the low density of RFLP or SSR markers in previous studies makes co-localization likely for most QTLs detected in the current study.

In addition to additive effect QTL, five pairs of epistatic QTL were also detected for ADF, CEL/NDF, IVNDFD, and NDF in our study. The majority of these pairs of epistatic QTL explained less than $10 \%$ of the phenotypic variations of each trait. These results suggest that epistasis also contributes to the complex nature of the cell wall components and digestibility of maize stalks, though the effects of epistasis are relatively weak.

Compared with previous QTL mapping studies of cell wall components at the anthesis stage, overlapping QTL were observed on bin 1.07 for ADF, bin 2.04 and 2.08 for NDF, and bin 9.03 for LIG in the present study (Krakowsky et al., 2003, 2005, 2006). Is the same gene playing roles in these overlapped QTL should be evaluated with fine mapping and more genetic approaches. A few colocalizations were also found between the current study and previous QTL mapping studies performed at silage stage, which included bin 9.02 for LIG content, IVDMD, and IVNDFD, bin 8.05 for IVDMD, and so on. The low resolution caused by the low density of RFLP or SSR markers in previous studies makes co-localization likely for some QTLs detected in the current study. These results revealed that a few genes are involved in cell wall biosynthesis consistently between anthesis stage and silage stage, and most genes that function in cell wall component accumulation have temporal specificity.

\section{Hotspots of QTL for Cell Wall Components and Digestibility}

Due to the significant correlation between cell wall traits and digestibility, it is easy to predict their genetic correlations and their co-localization in the genome. In a previous metaanalysis study, several regions were highlighted as hotspots of QTL for cell wall components and digestibility traits; these hotspots included bins 1.08, 1.11, 2.08, 3.07, 4.04, 5.04, 9.01, and 9.07 (Truntzler et al., 2010). In the current study, a QTL hotspot related to all six investigated traits was found on chromosome 9, which covers a large part of the maize genome of bin 9.02-9.03. Moreover, three regions (localized in bins 2.07, 7.03, and 8.01-8.02) were identified as overlapping QTL for several of the traits studied herein. These regions will be further investigated by association mapping or fine mapping to identify variants correlated with cell wall components and digestibility traits. This approach should be helpful in determining whether these overlapped regions were caused by pleiotropy, improve our understanding of cell wall biosynthesis, and provide molecular markers for improving forage quality.

\section{AVAILABILITY OF DATA AND MATERIALS}

The datasets supporting the conclusions of this article are included in the article and in its additional files. 


\section{AUTHOR CONTRIBUTIONS}

KL and HW carried out the experiments, analyzed the data, and wrote the manuscript; $\mathrm{XH}$ and $\mathrm{YW}$ assisted in data collection and analysis; FM and QW designed and performed the field experiments; and $\mathrm{CH}$ and $\mathrm{ZL}$ designed the study and helped to write the manuscript. All authors have read and approved the final version of the manuscript.

\section{FUNDING}

This study was supported by the National Key Research and Development Program of China (Grant No. 2016FYD0101201),

\section{REFERENCES}

Barriere, Y., and Argillier, O. (1993). Brown-midrib genes of maize: a review. Agronomie 13, 865-876.

Barriere, Y., Gibelin, C., Argillier, O., and Mechin, V. (2001). Genetic analysis in recombinant inbred lines of early dent forage maize. I: QTL mapping for yield, earliness, starch and crude protein contents from per se value and top cross experiments. Maydica 46, 253-266.

Barrière, Y., Guillet, C., Goffner, D., and Pichon, M. (2003). Genetic variation and breeding strategies for improved cell wall digestibility in annual forage crops. A review. Anim. Res. 52, 193-228. doi: 10.1051/animres:2003018

Barrière, Y., Riboulet, C., Méchin, V., Maltese, S., Pichon, M., Cardinal, A., et al. (2007). Genetics and genomics of lignification in grass cell walls based on maize as model species. Genes Genomes Genomics 1, 133-156.

Basten, C. J., Weir, B. S., Zeng, Z. B., and Typeset, I. L. (2005). QTL Cartographer, Version 1.17. Raleigh, NC: North Carolina State University.

Bhalla, A., Bansal, N., Kumar, S., Bischoff, K. M., and Sani, R. K. (2013). Improved lignocellulose conversion to biofuels with thermophilic bacteria and thermostable enzymes. Bioresour. Technol. 128, 751-759. doi: 10.1016/j. biortech.2012.10.145

Bohn, M., Schulz, B., Kreps, R., Klein, D., and Melchinger, A. (2000). QTL mapping for resistance against the European corn borer (Ostrinia nubilalis $\mathrm{H}$.) in early maturing European dent germplasm. Theor. Appl. Genet. 101, 907-917. doi: $10.1007 / s 001220051561$

Bukowski, R., Guo, X., Lu, Y., Zou, C., He, B., Rong, Z., et al. (2015). Construction of the third generation Zea mays haplotype map. bioRxiv. doi: 10.1101/026963

Cardinal, A. J., Lee, M., and Moore, K. J. (2003). Genetic mapping and analysis of quantitative trait loci affecting fiber and lignin content in maize. Theor. Appl. Genet. 106, 866-874. doi: 10.1007/s00122-002-1136-5

Cass, C. L., Lavell, A. A., Santoro, N., Foster, C. E., Karlen, S. D., Smith, R. A., et al. (2016). Cell wall composition and biomass recalcitrance differences within a genotypically diverse set of Brachypodium distachyon inbred lines. Front. Plant Sci. 7:708. doi: 10.3389/fpls.2016.00708

Chen, H. (2014). "Chemical composition and structure of natural lignocellulose," in Biotechnology of Lignocellulose: Theory and Practice, ed. H. Chen (Dordrecht: Springer), 25-71.

Cherney, J., Cherney, D., Akin, D., and Axtell, J. (1991). Potential of brown-midrib, low-lignin mutants for improving forage quality. Adv. Agron. 46, 157-198. doi: 10.1016/S0065-2113(08)60580-5

Chia, J. M., Song, C., Bradbury, P. J., Costich, D., Leon, N. D., Doebley, J., et al. (2012). Maize HapMap2 identifies extant variation from a genome in flux. Nat. Genet. 44, 803-807. doi: 10.1038/ng.2313

Churchill, G. A., and Doerge, R. W. (1994). Empirical threshold values for quantitative trait mapping. Genetics 138, 963-971.

Courtial, A., Méchin, V., Reymond, M., Grima-Pettenati, J., and Barrière, Y. (2013). Colocalizations between several QTLs for cell wall degradability and composition in the F288 × F271 early maize RIL progeny raise the question of the nature of the possible underlying determinants and breeding targets for biofuel capacity. Bioenergy Res. 7, 142-156. doi: 10.1007/s12155-013-9358-8 the National Natural Science Foundation of China (Grant No. 31171561), the Agricultural Science and Technology Innovation Program at CAAS, and the National Basic Research Program of China (973 Program) (Grant No. 2014CB138200).

\section{SUPPLEMENTARY MATERIAL}

The Supplementary Material for this article can be found online at: http://journal.frontiersin.org/article/10.3389/fpls.2017.01472/ full\#supplementary-material

DATA SHEET 1 | Summary of genetic map of the RIL population.

Dolstra, O., and Medema, J. H. (1990). "An effective screening method for improvement of cell-wall digestibility in forage maize," in Proceedings of the 15th Eucarpia congres Maize-Sorghum, ed. J. Hinterholzer (Baden: Federal Institute for Plant Production), 258-270.

Fan, J. B., Gunderson, K. L., Bibikova, M., Yeakley, J. M., Chen, J., Wickham, G. E., et al. (2006). Illumina universal bead arrays. Methods Enzymol. 410, 57-73. doi: 10.1016/S0076-6879(06)10003-8

Fontaine, A., Briand, M., and Barriere, Y. (2003). Genetic variation and QTL mapping of para-coumaric and ferulic acid. Maydica 48, 75-84.

Gall, H., Philippe, F., Domon, J.-M., Gillet, F., Pelloux, J., and Rayon, C. (2015). Cell wall metabolism in response to abiotic stress. Plants 4, 112-166. doi: $10.3390 /$ plants4010112

Ganal, M. W., Durstewitz, G., Polley, A., Bérard, A., Buckler, E. S., Charcosset, A., et al. (2011). A large maize (Zea mays L.) SNP genotyping array: development and germplasm genotyping, and genetic mapping to compare with the B73 reference genome. PLOS ONE 6:e28334. doi: 10.1371/journal.pone.00 28334

Gore, M. A., Chia, J. M., Elshire, R. J., Sun, Q., Ersoz, E. S., Hurwitz, B. L., et al. (2009). A first-generation haplotype map of maize. Science 326, 1115-1117. doi: $10.1126 /$ science. 1177837

Guzzo de Carli Poelking, V., Giordano, A., Ricci-Silva, M. E., Rhys Williams, T. C., Alves Pecanha, D., Contin Ventrella, M., et al. (2015). Analysis of a modern hybrid and an ancient sugarcane implicates a complex interplay of factors in affecting recalcitrance to cellulosic ethanol production. PLoS ONE 10:e0134964. doi: 10.1371/journal.pone.0134964

Hatfield, R. D., Jung, H.-J. G., Ralph, J., Buxton, D. R., and Weimer, P. J. (1994). A comparison of the insoluble residues produced by the Klason lignin and acid detergent lignin procedures. J. Sci. Food Agric. 65, 51-58. doi: 10.1002/jsfa. 2740650109

Jess, D. R. (1986). Relationships among soluble phenolics, insoluble proanthocyanidins and fiber in east African browse species. J. Range Manage. 39, 5-7. doi: 10.2307/3899675

Jiao, Y., Zhao, H., Ren, L., Song, W., Zeng, B., Guo, J., et al. (2012). Genome-wide genetic changes during modern breeding of maize. Nat. Genet. 46, 1039-1040. doi: $10.1038 / \mathrm{ng} .2312$

Kao, C. H., Zeng, Z. B., and Teasdale, R. D. (2004). Multiple interval mapping for quantitative trait loci. Genetics 167, 1987-2002. doi: 10.1534/genetics.103. 021642

Kebede, G., Assefa, G., Feyissa, F., and Alemayehu, M. (2016). Forage legumes in crop-livestock mixed farming systems: a review. Int. J. Livest. Res. 6, 1-18. doi: 10.5455/ijlr.20160317124049

Knapp, S., Stroup, W., and Ross, W. (1985). Exact confidence intervals for heritability on a progeny mean basis. Crop Sci. 25, 192-194. doi: 10.1007/ BF00288995

Kosambi, D. D. (2011). The estimation of map distance from recombination values. Ann. Hum. Genet. 12, 172-175.

Krakowsky, M., Lee, M., Beeghly, H., and Coors, J. (2003). Characterization of quantitative trait loci affecting fiber and lignin in maize (Zea mays L.). Maydica 48, 283-292. 
Krakowsky, M. D., Lee, M., and Coors, J. G. (2005). Quantitative trait loci for cellwall components in recombinant inbred lines of maize (Zea mays L.) I: stalk tissue. Theor. Appl. Genet. 111, 337-346. doi: 10.1007/s00122-005-2026-4

Krakowsky, M. D., Lee, M., and Coors, J. G. (2006). Quantitative trait loci for cell wall components in recombinant inbred lines of maize (Zea mays L.) II: leaf sheath tissue. Theor. Appl. Genet. 112, 717-726. doi: 10.1007/s00122-0050175-0

Lai, J., Li, R., Xu, X., Jin, W., Xu, M., Zhao, H., et al. (2010). Genome-wide patterns of genetic variation among elite maize inbred lines. Nat. Genet. 42, 1027-1030. doi: 10.1038/ng.684

Lander, E. S., and Botstein, D. (1989). Mapping mendelian factors underlying quantitative traits using RFLP linkage maps. Genetics 121, 185-199.

Li, H., Peng, Z., Yang, X., Wang, W., Fu, J., Wang, J., et al. (2013). Genome-wide association study dissects the genetic architecture of oil biosynthesis in maize kernels. Nat. Genet. 45, 43-50. doi: 10.1038/ng.2484

Li, K., Yan, J., Li, J., and Yang, X. (2014). Genetic architecture of rind penetrometer resistance in two maize recombinant inbred line populations. BMC Plant Biol. 14:152. doi: 10.1186/1471-2229-14-152

Li, Q., Yang, X., Xu, S., Cai, Y., Zhang, D., Han, Y., et al. (2012). Genome-wide association studies identified three independent polymorphisms associated with $\alpha$-tocopherol content in maize kernels. PLOS ONE 7:e36807. doi: 10.1371/ journal.pone.0036807

Li, X., and Chapple, C. (2010). Understanding lignification: challenges beyond monolignol biosynthesis. Plant Physiol. 154, 449-452. doi: 10.1104/pp.110. 162842

Lübberstedt, T., Melchinger, A. E., Klein, D., Degenhardt, H., and Paul, C. (1997a). QTL mapping in testcrosses of European flint lines of maize: II. Comparison of different testers for forage quality traits. Crop Sci. 37, 1913-1922. doi: 10.1186/ s12870-016-0816-2

Lübberstedt, T., Melchinger, A. E., Schön, C. C., Utz, H. F., and Klein, D. (1997b). QTL mapping in testcrosses of European flint lines of maize: I. Comparison of different testers for forage yield traits. Crop Sci. 37, 921-931. doi: 10.1186/ s12870-016-0816-2

Marita, J. M., Vermerris, W., Ralph, J., and Hatfield, R. D. (2003). Variations in the cell wall composition of maize brown midrib mutants. J. Agric. Food Chem. 51, 1313-1321. doi: 10.1021/jf0260592

Marriott, P. E., Sibout, R., Lapierre, C., Fangel, J. U., Willats, W. G., Hofte, H., et al. (2014). Range of cell-wall alterations enhance saccharification in Brachypodium distachyon mutants. Proc. Natl. Acad. Sci. U.S.A. 111, 14601-14606. doi: 10.1073/pnas.1414020111

Marten, G. C., and Barnes, R. F. (1979). Prediction of energy digestibility of forages with in vitro rumen fermentation and fungal enzyme systems. Opt. Photon. News 11, 196-198.

Méchin, V., Argillier, O., Hébert, Y., Guingo, E., Moreau, L., Charcosset, A., et al. (2001). Genetic analysis and QTL mapping of cell wall digestibility and lignification in silage maize. Crop Sci. 41, 690-697. doi: 10.2135/cropsci2001. 413690x

Meng, L., Li, H., Zhang, L., and Wang, J. (2015). QTL IciMapping: integrated software for genetic linkage map construction and quantitative trait locus mapping in biparental populations. Crop J. 3, 269-283. doi: 10.1016/j.cj.2015. 01.001

Murray, M. G., and Thompson, W. F. (1980). Rapid isolation of high molecular weight plant DNA. Nucleic Acids Res. 8, 4321-4325. doi: 10.1093/nar/8.19.4321

Papst, C., Melchinger, A., Eder, J., Schulz, B., Klein, D., and Bohn, M. (2001). QTL mapping for resistance to European corn borer (Ostrinia nubilalis $\mathrm{Hb}$.) in early maturing European dent maize (Zea mays L.) germplasm and comparison of genomic regions for resistance across two populations of F3 families. Maydica 46, 195-205.

Paterson, J. A., Bowman, J. P., Belyea, R. L., Kerley, M. S., and Williams, J. E. (1994). "The impact of forage quality and supplementation regimen on ruminant animal intake and performance," in Forage Quality, Evaluation, and Utilization, ed. G. C. Fahey (Madison, WI: American Society of Agronomy), 59-114.

Peiffer, J. A., Romay, M. C., Gore, M. A., Flint-Garcia, S. A., Zhang, Z., Millard, M. J., et al. (2014). The genetic architecture of maize height. Genetics 196, 1337-1356. doi: 10.1534/genetics.113.159152
Penning, B. W., Sykes, R. W., Babcock, N. C., Dugard, C. K., Held, M. A., Klimek, J. F., et al. (2014). Genetic determinants for enzymatic digestion of lignocellulosic biomass are independent of those for lignin abundance in a maize recombinant inbred population. Plant Physiol. 165, 1475-1487. doi: $10.1104 /$ pp.114.242446

Purcell, S., Neale, B., Toddbrown, K., Thomas, L., Ferreira, M. A. R., Bender, D., et al. (2007). PLINK: a tool set for whole-genome association and populationbased linkage analyses. Am. J. Hum. Genet. 81, 559-575. doi: 10.1086/519795

Riboulet, C., Fabre, F., Dénoue, D., Martinant, J., Lefevre, B., and Barrière, Y. (2008). QTL mapping and candidate gene research from lignin content and cell wall digestibility in a top-cross of a flint maize recombinant inbred line progeny harvested at silage stage. Maydica 53, 1-9.

Roussel, V., Gibelin, C., Fontaine, A., and Barriere, Y. (2002). Genetic analysis in recombinant inbred lines of early dent forage maize. II. QTL mapping for cell wall constituents and cell wall digestibility from per se value and top cross experiments. Maydica 47, 9-20.

Shenk, J. S., and Westerhaus, M. O. (1991). Populations structuring of near infrared spectra and modified partial least squares regression. Crop Sci. 31, 1548-1555. doi: 10.2135/cropsci1991.0011183X003100060034x

Shenk, J. S., and Westerhaus, M. O. (1994). "The application of near infrared reflectance spectroscopy (NIRS) to forage analysis," in Forage Quality, Evaluation and Utilization, ed. G. C. Fahey Jr. (Madison, WI: Soil Science Society of America), 406-449.

Shutu, X., Dalong, Z., Ye, C., Yi, Z., Shah, T., Ali, F., et al. (2012). Dissecting tocopherols content in maize (Zea mays L.), using two segregating populations and high-density single nucleotide polymorphism markers. BMC Plant Biol. 12:201. doi: 10.1186/1471-2229-12-201

Simmons, B. A., Loqué, D., and Ralph, J. (2010). Advances in modifying lignin for enhanced biofuel production. Curr. Opin. Plant Biol. 13, 312-319. doi: 10.1016/j.pbi.2010.03.001

Struik, P. C. (1983). Physiology of Forage Maize (Zea mays L) in Relation to Its Production and Quality. Ph.D. thesis, Landbouwhogeschool Wageningen, Wageningen.

Truntzler, M., Barriere, Y., Sawkins, M. C., Lespinasse, D., Betran, J., Charcosset, A., et al. (2010). Meta-analysis of QTL involved in silage quality of maize and comparison with the position of candidate genes. Theor. Appl. Genet. 121, 1465-1482. doi: 10.1007/s00122-010-1402-x

Vermerris, W., Saballos, A., Ejeta, G., Mosier, N. S., Ladisch, M. R., Carpita, N. C., et al. (2007). Molecular breeding to enhance ethanol production from corn and sorghum stover. Crop Sci. 47(Suppl. 3), S142. doi: 10.2135/cropsci2007.04. 0013IPBS

Yan, J., Shah, T., Warburton, M. L., Buckler, E. S., Mcmullen, M. D., and Crouch, J. (2009). Genetic characterization and linkage disequilibrium estimation of a global maize collection using SNP markers. PLoS ONE 4:e8451. doi: 10.1371/ journal.pone.0008451

Yan, J., Yang, X., Shah, T., Sánchez-Villeda, H., Li, J., Warburton, M., et al. (2010). High-throughput SNP genotyping with the GoldenGate assay in maize. Mol. Breed. 25, 441-451. doi: 10.1007/s11032-015-0335-0

Yang, X., Xu, Y., Shah, T., Li, H., Han, Z., Li, J., et al. (2011). Comparison of SSRs and SNPs in assessment of genetic relatedness in maize. Genetica 139, 1045-1054. doi: 10.1007/s10709-011-9606-9

Zeng, Z. B. (1994). Precision mapping of quantitative trait loci. Genetics 136, 999-1009.

Conflict of Interest Statement: The authors declare that the research was conducted in the absence of any commercial or financial relationships that could be construed as a potential conflict of interest.

Copyright (c) 2017 Li, Wang, Hu, Ma, Wu, Wang, Liu and Huang. This is an openaccess article distributed under the terms of the Creative Commons Attribution License (CC BY). The use, distribution or reproduction in other forums is permitted, provided the original author(s) or licensor are credited and that the original publication in this journal is cited, in accordance with accepted academic practice. No use, distribution or reproduction is permitted which does not comply with these terms. 